\title{
MINISSÉRIES HISTÓRICAS E COMUNICAÇÃO POR OBJETOS. NOTAS SOBRE OS FIGURINOS E CENÁRIOS DE "PRIMO BASÍLIO” E “OS MAIAS"
}

\author{
OBJECTS CULTURE AND AUDIOVISUAL PERCEPTIONS: \\ NOTES ABOUT THE HISTORICAL MINISERIES \\ "PRIMO BASÍLIO” AND "OS MAIAS" \\ CULTURA DE LOS OBJECTOS Y DE LAS PERCEPCIONES AUDIOVISUALES \\ EM LAS MINISERIES HISTORICAS "PRIMO BASÍLIO” Y "OS MAIAS"
}

Solange Wajnman

Professora e Pesquisadora da Linha de

Pesquisa "Configurações de Linguagens e Produtos Audiovisuais na Cultura Midiática" do Programa de Mestrado em Comunicação da UNIP.wajnman@aclnet.com.br

Maria Gabriela S.M.C. Marinho

Professora e Pesquisadora da Linha de Pesquisa

"Cultura, Comunicação e Dinâmica Social", do Programa de Mestrado em Ciências Humanas e Sociais da

Universidade Federal do ABC (UFABC). gabriela.marinho@ufabc.edu.brou gabiol@uol.com.br

\section{Resumo}

Na perspectiva da cultura dos objetos e da percepção audiovisual, o artigo investiga, analisa e contrapõe cenários e figurinos construídos para as minisséries históricas Primo Basílio (1988) e Os Maias (2001), ambas adaptadas da obra de Eça de Queiroz e produzidas pela Rede Globo de Televisão. Pretende-se pensar de que modo a configuração, construção e materialização do universo ficcional para a televisão expressa, a partir dos objetos, os modos pelos quais a burguesia portuguesa do século XIX é percebida e veiculada pela maior empresa brasileira de comunicação audiovisual. $\mathrm{O}$ argumento central funda-se na idéia de que os objetos não somente se prestam a expressar um sentido para a narração, mas no fato de que, através deles, a Rede Globo (re) configura e (re) apropria aspectos da vida social portuguesa.

Palavras-chave: Teoria das Materialidades; Campo Não-Hermenêutico; Comunicação por Objetos

\section{Esta obra está licenciada sob uma Licença Creative Commons}




\begin{abstract}
In the perspective of objects culture and audiovisual perception, the article investigates, analyzes and counteracts sceneries and costumes built up for the historical miniseries Primo Basilio (1988) and Os Maias (2001), both adapted from Eça de Queiroz work and produced by Rede Globo de Televisão. Intended to thinking on what way the configuration, building and materialization of the fictional universe for the express television, starting from the objects, the ways the Portuguese bourgeoisie from the 21th century is perceived and broadcast by the largest Brazilian company of audiovisual communication. The central argument is based on the idea that the objects not only are useful to express a sense for the narration, but in the fact that, through them, Rede Globo (re) configures and (re) appropriates aspects of Portuguese social life.
\end{abstract}

Key-words : theory of materiality, not hermeneutic field, communication by means of objects

\title{
Resumen
}

El artículo analisa la cultura de los objetos y de las percepciones audiovisuales desde la perspectiva de la Teoria de las Materialidades em las produciones Primo Basílio (1988) y Os Maias (2001), obras originales del escritor portugués Eça de Queiroz escritas en el siglo XIX, montadas por la empresa brasileña Rede Globo de Televisão. La investigación trata de la configuración, construcción y materialización del universo ficcional, desde los objectos, y de los modos en los que la burguesía portuguesa se expresa mediante tales organizaciones.

Palabras clave: Teoria de las Materialidades, Analisis del Objectos, Campo No Hermeneutico

\section{INTRODUÇÃO AO CAMPO DAS MATERIALIDADES E AO ESTUDO DAS MINISSERIES}

O campo das Materialidades ou campo Não-Hermenêutico é uma perspectiva teóricometodológica que começa a se desenvolver no meio acadêmico nacional e toma como objeto a análise dos elementos materiais presentes na Comunicação Audiovisual. No país, a abordagem vem se desenvolvendo a partir, sobretudo, dos estudos realizados nos programas de pósgraduação em Comunicação da Universidade Estadual do Rio de Janeiro (UERJ) e da Universidade Federal de Minas Gerais (UFMG), embora outras contribuições possam também ser identificadas a partir de pesquisadores individuais ou grupos de pesquisa em diferentes instituiçõos. Por se tratar de um campo de estudos capaz de oferecer investigações inovadoras, optamos por cotejar e tematizar em conjunto a materialidade da comunicação das minisséries Primo Basílio (1988) e Os Maias (2001), ambos produzidas pela Rede Globo de Televisão, conforme exposto a seguir. 
Inicialmente, a abordagem da vida social das classes abastadas portuguesas, a alta burguesia e a aristocracia decadente do final do século XIX, presente nas duas minisséries oferece um contraponto temático relevante para a análise. Embora em Primo Basílio, o tom seja mais naturalista e em Os Maias a noção do trágico conflite com o realismo, nas duas obras os objetos materiais são abundantemente descritos. Do mesmo modo, nas duas adaptações, produzidas de modo a assegurar fidelidade ao original, conforme atestam os diversos estudos dedicados a esse tipo de análise, a presença e a diversidade dos objetos é uma constante. Contudo, a forma pelas quais os objetos do cenário e figurino (re) configuram a vida social da elite dirigente sugere diversas apropriações, assinala o depoimento da Antonio Casimiro, cenógrafo português consultor das minisséries, cujas observações serão retomadas mais adiante.

O segundo elemento que ampara a análise conjunta das duas minisséries refere-se ao cotejamento das condições tecnológicas da produção. Ou seja, permite uma análise da capacidade técnica da própria Rede Globo de Televisão. Nessa direção, também a investigação acerca dos dois momentos de exibição, respectivamente 1988 e 2001, oferece diferentes elementos em torno das questões de materialidade, como assinalado acima. Buscamos, portanto, investigar o potencial dos equipamentos de gravação tais como câmeras, luzes e materiais de cenário, além de averiguar as maneiras pelas quais a emissora coleta os dados de produção, arquiva e disponibiliza a memória de minisséries e o tipo de tecnologia de pesquisa empregado.

Procuramos, ainda, apontar para a necessidade de descrições técnicas detalhadas do cenário e figurino, observando texturas, cores, formas e estilos, sensações sinestésicas, com o objetivo de estabelecer um estudo do significante a partir dos estudos da teoria da materialidade. Por fim, propomos comparações entre os objetos identificados nas minisséries e imagens do vestuário, mobiliário e decoração do século XIX encontrados em desenhos, pinturas e livros históricos no sentido de avaliar o grau de liberdade assumido pela emissora ao efetuar aproximações, desvios ou estilizações da época retratada.

\subsection{O Tema e seus Problemas}

Os objetos mediam a nossa relação com o ambiente físico, histórico e social. É sempre possível abordar uma época, uma cultura ou grupo social a partir da investigação dos usos, 
apropriações e natureza dos seus materiais e objetos. Os objetos são, portanto, um excelente ponto de partida para a pesquisa em ciências humanas e sociais. Algumas vertentes da Antropologia, da História e, recentemente, da própria Comunicação, fazem do estudo do objeto um viés epistemológico. Não é difícil compreender a riqueza deste viés. Pela funcionalidade do objeto pode-se compreender como a vida é expressa em costumes e hábitos que dizem respeito ao corpo, ao tempo e às sociabilidades. Pela materialidade dos objetos, pode-se identificar o grau de desenvolvimento tecnológico de uma dada sociedade, bem como a apropriação da natureza e o condicionamento dos sentidos, especialmente no que diz respeito à relação do suporte dos objetos com o corpo.

Como se dá a reconstrução de uma narrativa como a descrita por Eça de Queiroz, em que os objetos que configuram a vida social da burguesia do século XIX são apreendidos pela cultura contemporânea das mídias? O que esperar, quando a apresentação desta mesma narrativa retoma tais objetos em um suporte tecnológico distinto daquele que se deu o seu nascedouro, no caso, originalmente pela impressa do livro?

Pode-se indagar, ainda, de que modo tais objetos, em especial, cenários e figurinos, colocados em imagem por recursos tecnológicos contemporâneos, podem materializar a vida burguesa do século XIX e como a comunicação destes se distingue daquela veiculada pelo livro? Enfim, como se constrói uma narrativa em que os objetos estão em permanente destaque do ponto de vista de pesquisa, produção e exposição em imagem?

A discussão sobre as minisséries Primo Basílio e Os Maias são abundantes no meio acadêmico. A partir do material disponível buscamos trabalhos que tratassem dos objetos em seu tratamento televisivo ou reflexões acerca da narrativa pelos objetos. Contudo, em sua grande maioria, os estudos realizados analisam sobretudo questões de adaptação do romance para a televisão ou investigam as relações entre cultura erudita e popular. Todavia, encontramos algumas pistas em torno da problemática dos objetos, embora incompletas.

Ao analisar as adaptações dos dois livros de Eça de Queiróz para a televisão, alguns artigos introduzem o que chamam de semiologia dos objetos. Apontam que a linguagem dos objetos seria organizada tanto pelo escritor dos romances quanto pela produção da telenovela de modo a despertar sensações e aguçar a percepção do leitor e/ou receptor. Em suas análises, duas autoras asseguram que a energia inculcada nos objetos por Eça foi capturada como estratégia 
técnica para as minisséries. Tal recurso personificaria o objeto inerte dotando-o de uma série de qualidades evocadas, transferência sentimental e qualitativa, conforme assinalado a seguir, a narrativa parte

do detalhismo na descrição dos personagens e do espaço no desenrolar da ação, que na minissérie é evidenciado pelos cortes e movimento de câmera, enfocando os objetos que compõem os cenários, num jogo estático e ao mesmo tempo dinâmico que caracteriza sua simbologia através das aproximações e distanciamentos dos planos de filmagem, de acordo com a leitura do diretor (MOREIRA e PAIVA, 2007, p.6).

No caso de Primo Basílio, por exemplo, o exagero descritivo do cenário serve para demonstrar o estado de espírito da protagonista. A câmera descreve sua psicologia por meio de sua relação com os objetos. As autoras observam:

(...) através de sua descrição (da câmera) é possível notar que Luíza é mostrada como se fosse um objeto de decoração para a casa de Jorge. Ou está vestida ao piano, ou ao toucador, ou na poltrona a ler seus romances ou na mesa a tomar café. Na casa há muitos vitrais e espelhos, há cenas em que os personagens são mostrados através dos espelhos que compõem o cenário, índices da fragilidade educacional e moral de Luisa, marcada por uma frivolidade indiscutível que intensifica e acompanha a sua personalidade infantil e frágil. (Idem, 2007: p.8)

Os objetos servem aqui para compor o universo psicológico da personagem. A autora ainda traz alguns exemplos, como o das paredes manchadas, "como se indicasse o estado moral de Luisa adúltera", e "a colcha de retalhos estendida sobre a cama, como um indício de que a vida da personagem estava como aquela colcha, toda retalhada" (2007: p.9). Como vimos, nessa análise da minissérie Primo Basílio, os objetos "falam” dos conteúdos da narrativa, auxiliam sem sua composição e são retrabalhados pela tecnologia das luzes, recursos de câmeras, cortes, aproximações, entre outros aspectos técnicos. Por este viés, a análise sobre Os Maias é ainda mais instrutiva em relação à semiologia dos objetos. Flory e Moreira demonstram como os objetos no espaço fílmico têm um importante papel na configuração do elemento trágico, conforme observam:

As personagens definem-se pela ação, mas são os objetos que se encarregam de indiciar, explicar e preparar as situações, estabelecendo um conjunto de conflitos, mutuamente ligados pelo nexo de causa e efeito, configurando-se a 
"ação completa", indispensável à tragédia. (...) Na abertura da minissérie, o Ramalhete configura-se como um verdadeiro personagem, visto através da focalização da câmera, que vai destacando objetos e voltando a fatos passados por meio de cenas rápidas ou do narrador em off que lhes explica sentido e a existência.

Constituindo-se como elementos ativos da diegese, torna-se indispensável à análise da funcionalidade das descrições dos objetos e do espaço fílmico na caracterização do trágico e na montagem dramática da cena e do cenário.(..) (FLORY e MOREIRA, 2006; 167).

Nesse sentido,

(...) a ação trágica presentifica-se por meio do encadeamento de situações interligadas, onde as descrições e os objetos fazem emergir, a par da linguagem dramática dos diálogos e monólogos interiores, outras linguagens cênicas como vestuário, iluminação, ruídos, penteados, além da "marcação" que surge nas constantes indicações de gestos e movimentos que o próprio Eça aponta em seu texto narrativo e que a leitura de Maria Adelaide Amaral e sua equipe concretizam, artisticamente na mídia televisiva (2006: p.168).

As autoras acertadamente analisam a semiologia dos objetos colocados em imagem. As considerações são bem pertinentes, entre outras razões, por identificar que a narrativa televisiva centrou-se em uma perspectiva que reafirma a dimensão audiovisual por meio da qual os objetos têm grande funcionalidade. No entanto, a nosso ver, esta semiologia dos significados não esgota toda a complexidade acerca das possibilidades de comunicação pelos objetos, como argumentamos a seguir.

Ora, ao telespectador não é veiculada somente a mensagem do conflito inerente à trama da história que se narra. Ali estão presentes elementos que expressam a dinâmica de uma sociedade específica, sua época e organização social. Nesse sentido, consideramos que é possível às investigações que abordam as dimensões materiais como objeto de análise transcender a trama narrativa. Ou, dito de outro modo, é possível demonstrar que os objetos são portadores de significados não apenas no interior da trama. Para além da narrativa, carregam consigo informações de sua base tecnológica e são testemunhas de um determinado tempo histórico. Além da dimensão histórica, o objeto promove e aciona uma relação sinestésica que está aquém e, por vezes, além do sentido. 
Nessa perspectiva, consideramos que a linguagem audiovisual também deve ser analisada em sua dimensão sinestésica propiciada pela inserção que o objeto em imagem acarreta. No caso da presente análise, essa dimensão assume um caráter ainda mais complexo em razão dos processos de configuração e reconfiguração histórica operados pela produção das minisséries. Para as autoras acima citadas, os objetos fílmicos somente falam de conteúdos internos à diegese. Em nossa perspectiva, eles podem falar também de outras maneiras e que é possível tematizá-lo sem que necessariamente se recorra aos significados internos da trama e da narrativa.

\subsection{A Perspectiva Teórica das Materialidades e a Análise das Minisséries}

Para avançarmos na análise apontada acima, optamos por retomar a questão teórica, conforme detalhado a seguir, na perspectiva da teoria das materialidades proposta por Hans Ulrich Gumbrecht. Teórico alemão influenciado pelas idéias de Hans Robert Jauss , Wolfgang Iser, Gumbrecht e ainda McLuhan "não se direciona para a interpretação de símbolos, palavras, textos, enredos, tramas ou narrativas. Seguindo por outra vertente, privilegia o papel da materialidade do corpo do sujeito, do suporte do meio de comunicação e de seus condicionamentos sócio-culturais que concorrem para a configuração do sentido. Em suas palavras: "Não mais procuramos identificar o sentido, para logo resgatá-lo; porém indagamos das condições de possibilidade de emergência das estruturas de sentido. (GUMBRECHT, 1988, p.147"

Entre os fundamentos filosóficos para esta opção teórico-metodológica, encontram-se pressupostos que identificam a perda de referências tradicionais em termos de temporalidade e totalidade e o descentramento do sujeito. Não caberia, nos limites deste artigo, aprofundar a discussão acerca de tais balizamentos. Porém, oferecemos alguns elementos em torno de sua visão sobre os fundamentos materiais da comunicação como uma ferramenta útil para a análise da problemática aqui proposta. Neste sentido, recorremos a Bernadette Lyra:

(...) a teoria da materialidade é uma teoria que se faz em torno dessa reconstrução da materialidade. Ela passa, de modo conjunto, pelo meio de comunicação e pelas instituições responsáveis pela reprodução da cultura. As relações entre os meios de comunicação, instituições e hábitos de determinada 
época são vistas como o horizonte de condições em que os elementos das estruturas de sentido podem se organizar. As pesquisas, então, se tecem em volta dessas relações e, para serem investigadas, exigem um reconhecimento sóciohistórico e de constituição material dos meios. Assim, a pesquisa deve levar em conta tanto a reconstrução da época em que o objeto foi produzido, como as circunstâncias sócio-culturais que cercam essa época, quanto a tecnologia que permitiu a produção do objeto, de acordo com a época (LYRA apud ROCHA, 2005. pp 21-28),

No domínio das materialidades, que tem como proposta um campo não-hermenêutico, prioriza-se, portanto, a tematização do significante sem necessariamente associá-lo ao significado. Assim, o pesquisador deve estudar o ato de comunicação em relação ao suporte material tendo como princípio a idéia de que a materialidade do meio de transmissão influencia e até certo ponto determina a estruturação da mensagem comunicacional. Deve, ao mesmo tempo, considerar em seu esforço de análise a relação do objeto com os seus usuários, assim como as condições históricas e materiais que abarcam tanto materialidade do objeto como o próprio usuário. Walter Benjamin, Marshall McLuhan e Michel Foucault foram, segundo Gumbrecht, autores cujos trabalhos interessam e se relacionam ao campo de análise não-hermenêutica.

Amparadas pelas contribuições dos autores acima enunciados, apresentaremos a seguir as vertentes teóricas inseridas no recorte "materialidade da comunicação".

\subsection{A Linguagem Sinestésica dos Objetos em Imagem}

As contribuições do filósofo Walter Benjamin podem ser assinaladas como as proposições teóricas que inicialmente nos motivaram a refletir sobre os objetos, em especial suas considerações acerca das formas de percepção impostas pela obra de arte na era de sua reprodutibilidade técnica. Nessa direção, podemos identificar e analisar as diferenças existentes entre a produção televisiva executada para uma massa de telespectadores e mediada pela tecnologia do audiovisual em relação, por exemplo, perante a tecnologia envolvida na confecção do livro. De forma similar, e por comparação, argumentamos que a maneira como a mesma narrativa é desenvolvida por imagens supõe um tipo de percepção diferente daquela expressa pelo livro impresso. 
Rápida, fragmentada e com marcas táteis e sinestésicas, a produção televisiva assume um estatuto diferenciado da comunicação impressa. Pioneiro nesse tipo de abordagem, Marshall McLuhan introduziu a discussão acerca das impressões corporais provocadas pelas emissões televisivas. A compreensão das relações sinestésicas apontadas por McLuhan pode ser aprofundada a partir das considerações de Silvia Jardim, como exposto a seguir:

(...) a tecnologia da televisão representou o fim da "Galáxia de Gutenberg", o marco do entendimento e superação das percepções das sociedades letradas que predominou no mundo ocidental por muitos séculos. Enquanto as tecnologias mecânicas advindas da imprensa e da Revolução Industrial nos fornecem uma percepção recortada e serializada, as tecnologias da eletricidade trazem percepções ligadas à simultaneidade e à configuração. As linhas de produção da Revolução Industrial são lineares, dividem o processo de fabricação em várias etapas e especializam o trabalhador, que conhecendo somente uma parte da produção perde a visão do todo. As tecnologias eletrônicas, por sua vez, são baseadas no circuito onde as consequiências de qualquer ação acontecem ao mesmo tempo, de forma simultânea, requisitando a retro-alimentação e a participação.

$\mathrm{O}$ meio de comunicação que caracteriza a sociedade mecanicista é a imprensa. $\mathrm{O}$ ato de leitura através da utilização do código da escrita requer o uso de apenas um dos sentidos para a sua compreensão: a visão. Através deste instrumento de comunicação temos uma percepção recortada, ou seja, só conseguimos perceber uma parte do todo, já que usamos somente um dos sentidos, deixando de lado os outros. Isto explica porque as sociedades pautadas na imprensa podem ser caracterizadas por um modo antropocêntrico de ver o mundo. Elas somente percebem a si próprias e consideram de menor valor todo conhecimento das sociedades orais.

A sociedade contemporânea, no entanto, tem como meio de comunicação mais influente a televisão, e o ato de assisti-la exige que utilizemos simultaneamente vários outros sentidos além da visão, implicando na nossa participação e envolvimento. Este novo tipo de percepção aparece juntamente com o desenvolvimento das teorias de sistemas complexos e com as questões ambientais, ou seja, a partir delas o homem contemporâneo sente-se como participante de uma intricada rede de relações interdependentes, com a qual tem o poder de interagir.

Analisando o acoplamento do corpo humano a estas tecnologias podemos afirmar que a escrita nos leva aos processos cognitivos ligados ao isolamento, concentração e reflexão. Ao contrário, as tecnologias eletrônicas permitem processos cognitivos de participação, envolvimento e experiência sensorial.

Para acompanhar a narrativa seriada de uma novela, por exemplo, temos que assisti-la todos os dias armazenando dados de maneira sinestésica (através da visão, audição e tatilidade), desta forma as informações dos capítulos posteriores vão se completando.(JARDIM, 2008). 
Silvia Jardim nos inspira igualmente para identificar na comunicação pelos objetos, em especial os figurinos e cenários colocados em imagem, elementos táteis que se insuflam ao olhar do telespectador. Ela observa:

O figurino, assim como o cenário, as falas e gestos dos atores, vão se articulando de maneira a construir uma mensagem idealizada por produtores, roteiristas, diretores, figurinistas e cenógrafos. Esta mensagem bombardeia os sentidos do telespectador que se sente parte ativa do processo comunicacional (JARDIM, 2008).

Desse modo, a comunicação dos romances de Eça de Queiroz reorganizada para a televisão, isto é pela tecnologia audiovisual, supõe igualmente o emprego da visão, audição e tatilidade, em flagrante distinção em relação ao ato de ler. Por meio das minisséries, os objetos descritos no romance adquirem uma vida que é recebida e percebida sinestesicamente pelo corpo do telespectador. Em decorrência, os sentidos se misturam: sente-se com os olhos aquilo que seria reservado ao toque, como a tatilidade aveludada de um sobretudo ou a leveza de um vestido de organza da protagonista. Conhece-se pelos olhos o aconchego aristocrático dos tons de vermelho que o palacete dos aristocratas ostenta ao mesmo tempo em que se ouve seu discurso verbal. Ficamos sabendo do estilo de vida das camadas dominantes com nosso corpo. A linguagem sinestésica dos objetos de cenário e figurino é amplificada e intensificada pelos recursos de luzes e câmeras que desponta como uma característica da linguagem audiovisual.

Como observa J.B Cardoso (2009: p.78) ainda que a natureza da malha eletrônica da televisão chape a imagem e reduza as qualidades do cenário, existem trabalhos experimentais realizados nos últimos anos que inovaram no uso de determinadas textura, materiais e padrões de tecidos -em especial as listras, os xadrezes e as padronagens reduzidas repetitivas-, assim como no uso das cores -em especial, o vermelho e os tons saturados-, ou ainda movimentos -como as linhas espirais ou diagonais. Ele observa:

Os novos processos de captação, transmissão e recepção da imagem, entre os quais se incluem o sistema digital e as telas de alta resolução, somados à aceitação dos efeitos naturais causados pela retícula eletrônoica, como o moiré, trouxeram para nossa tela as texturas extremamente detalhadas dos salões da aristocracia portuguesa da metade do século XIX, as cores saturadas e contrastantes (...), as listras, as flores e os xadrezes, os vermelhos e vinho (CARDOSO, 2009: p.78). 
Os Maias, em especial, usaram e abusaram desta linguagem tátil nos seus objetos texturas.

\subsection{Apropriação e Reconfiguração dos Objetos Literários pela Minissérie}

Por outro lado, a linguagem sinestésica envolve também as maneiras pelas quais os objetos de decoração e da indumentária são organizados para aí serem colocados. Se a narrativa de Eça de Queiróz já traz como importante recurso literário, a descrição de objetos enquanto como elemento de descrição da aristocracia e burguesia portuguesa do século XIX, pode-se indagar como esta mesma idéia de vida da elite se (re) configura na a partir dos objetos cênicos de uma minissérie contemporânea.

Não se trata mais de enxergar como símbolos os objetos descritos pela câmera, mas reconhecê-los como parte integrante da narrativa enquanto significantes ativos (como surgem enquanto hábitos). Podemos compreender como e o quê estes objetos, agora reorganizados para a minissérie, contam do estilo de vida daquele segmento social. Desse modo, nossa pesquisa histórica sobre o tipo de ambientação dessas classes confirma o uso destes objetos. Jean Poirier (1999), em sua pesquisa O Homem e o Objeto observa:

Quanto mais se aproximava o fim do século XIX, mais o tapeceiro suplantava o arquiteto. $\mathrm{O}$ estilo decorativo refletia o apego a tudo quanto fosse bugiganga e vestígio. Os salões de recepção tendiam a tornar-se verdadeiros bazares, onde o dono da casa expunha a mostra todas as riquezas sem atender à beleza, à raridade ou ao estilo: assim nascera no segundo Império aquilo a que poderíamos chamar " estilo vitrina" ou " enche-tudo", que desde então não tem deixado de agradar.” (POIRIER, 1999: p.162)

Em maior ou menor escala os ambientes duas minisséries traziam detalhes decorativos. Em especial, as descrições de Eça de Queiroz de ambientes entulhados de objetos de vários certos ambientes de Os Maias correspondem ao trabalho da produção da tv e são indicativas do gosto da elite da época. Além disso, o excesso de roupas brancas também pode, por exemplo, indicar a presença de um "adultério elegante". Está na mesma direção em que um tipo de tecido ou objeto especialmente demarcado pode ser considerado distintivo da classe social. 
Assim, é necessário, sobretudo, compreender como estes objetos são utilizados e apropriados pela produção da minissérie. Ou seja, como são reconfigurados na atualidade, considerando-se as distâncias técnicas e tecnológicas implicadas na escala temporal de mais de cem anos que separa a obra impressa de sua adaptação para televisão. Abre-se, em decorrência, um amplo repertório de indagações: que processos, materiais e adaptações foram utilizados? Distorções podem ser identificadas? Qual a relação entre objetos "de época" e similares contemporâneos?

Neste aspecto particular, as proposições de Foucault enunciadas na "Arqueologia do Saber" são de grande valia. Na obra em questão, Foucault discute a relação entre o fato histórico e sua representação, quando assinala:

(...) $\mathrm{O}$ documento não é o feliz instrumento de uma história que seria em si mesma, e de pleno direito, memória: a história é, para uma sociedade, uma certa maneira de dar status e elaboração à massa documental de que ela não se separa. (FOUCAULT, 2004, p.7-8).

As observações de Foucault são bem pertinentes em relação às minisséries Primo Basílio e Os Maias uma vez que suas adaptações tentam ser fiéis ao relato histórico de Eça de Queiroz. Apesar do esforço de fidelidade à obra, a adaptação, em especial para a televisão, passa necessariamente pelo processo de reconfiguração histórica. Ou seja, os objetos descritos por Eça pertencem a uma sociedade específica e a um tempo determinado que se foram. No presente, trata-se de outra sociedade, outra conjuntura histórica que irá se apropriar daquela produção e, necessariamente, recriá-la. Em decorrência, constituem-se indagações tais como se utilizam materiais do presentes - tecidos, objetos decorativos, cenários - para reconstruir uma ambiência de época? Como se elabora materialmente aquilo que Eça de Queiroz descreveu com palavras?

Neste sentido é importante a observação de Antonio Casimiro ${ }^{1}$, cenógrafo e figurinista português que forneceu consultoria para a elaboração de Primo Basílio e Os Maias, que afirma:

(...) a TV Globo, através do seu diretor Daniel Filho, me convidou para colaborar nesse mesmo tema (Primo Basílio) juntamente com o cenógrafo e diretor de arte Mário Monteiro, que atuou como consultor e supervisor de todo espaço cênico em estúdio e em locação exterior, bem como figurinos. Anos mais

\footnotetext{
${ }^{1}$ Antonio Casimiro nos concedeu entrevistas pessoalmente e por correio eletrônico em vários momentos dessa pesquisa durante os anos 2009 até 2011.
} 
tarde uma outra equipe da TV Globo veio a Lisboa produzir "Os Maias" e aí estou novamente a colaborar num texto visto e revisto de Eça de Queiroz. Desta vez havia dinheiro a mais e pesquisa a menos. A sociedade portuguesa na altura não era tão ostensiva. Os produtores brasileiros abusaram do luxo talvez por exigência do diretor. Lisboa não era Paris, nem Londres, tão pouco Viena de Áustria. Não ficou retratado o ambiente lisboeta do fim do século XIX e não quiseram aceitar muitos dos conselhos havidos, embora o resultado final fosse uma beleza. (Depoimento para as autoras, grifo nosso)

\subsection{A Produção Tecnológica}

Percebe-se com mais clareza no comentário do profissional português a problemática que procuramos evidenciando. Ou seja, a problematização da reconfiguração da sociedade por meio dos objetos de cena que compõem as minisséries Primo Basílio e Os Maias. Evidentemente estamos aqui enunciando a problemática, que merecerá tratamento mais aprofundado em investigações posteriores.

Contudo, cabe reafirmar que a natureza dos recursos tecnológicos seguramente acarretou implicações de várias ordens na produção e, em decorrência, na percepção das duas minisséries. Equipamentos de gravação tais como câmeras, luzes, materiais de cenário são importantes enquanto configuradores dos objetos. Coube-nos, portanto, examinar em que registro tecnológico a minissérie Primo Basílio (1988) e, mais de uma década depois, Os Maias (2001), se enquadraram.

Enquanto campo não-hermenêutico e na perspectiva da materialidade da comunicação, consideramos também as a maneiras pelas quais a emissora arquiva e disponibiliza sua memória. Como ela registra o dado e o disponibiliza para a pesquisa interna e para o público é também um dos vértices dessa pesquisa. A preocupação aqui é perceber como as condições histórias e tecnológicas se modificam e ao se modificarem transformam também "o approche" com a narrativa queiroziana.

Dentro desse contexto tivemos acesso ao banco de dados departamento de memória da Rede Globo na cidade cenográfica da Rede Globo e encontramos cerca de 587 resultados de cenografia, figurinos e objetos acerca das duas minisséries, sendo a grande maioria de Os Maias. Isto se explica pelo fato de que o departamento de memória exista apenas a partir do ano 2000 e 
que a técnica de digitalização ainda não tenha alcançado os documentos de Primo Basílio (1988).

No que diz respeito aos dados de produção de Primo Basílio encontramos a cobertura quase completa das plantas do cenário da cidade cenográfica. São plantas ainda desenhadas à mão, sem nenhum tratamento informático onde estão esboçadas as casas dos personagens Jorge e Luisa e algumas outras indeterminadas que reconstituíam os ambientes de Lisboa. Com a indicação escrita à caneta dos materiais encontramos uma riqueza de detalhes para as indicações de materiais tais como tubo em PVC, latão, corrimão de madeira, grade de ferro , balaustre em fibra entre outros elementos. Chamou-nos a atenção as indicações de materiais sintéticos que deveriam imitar materiais nobres como a peroba e os revestimentos em tecidos superiores.

Diferentemente de Os Maias, as cenas exteriores de Primo Basílio não foram feitas em Portugal, por demandar maior investimento financeiro. Elas foram reconstituídas em Bonsuceso e gravadas em um terreno plano de Guaratiba, cidade cenográfica que antecede o Projac de Jacarepaguá. Para muitas destas cenas a solução foi o chroma key (recurso que permitiu a impressão de figura presencial e fundo projetado) e a técnica do newsmate (técnica que possibilita a colocação de uma imagem recortada por outra), essa última utilizada para a figuração do Theatro São Carlos, um barroco do século XVIII. Na opinião de Antonio Casimiro, que nos prestou depoimento os interiores do ambiente queiroziano foram reproduzido mas a reconstituição desse ambiente nas cenas externas não foi bem feita.

Com a evolução tecnológica os recursos técnicos se aprimoraram de maneira geral. Assim, por exemplo, enquanto em Primo Basílio há poucas referências de catalogação dos objetos de cenário e as plantas são feitas à mão em Os Maias tudo se organiza em pranchas. Em Primo Basílio, em 1988, eram estes os itens da ficha: programa, cenário, local de gravação e a data. A ficha básica de "Os Maias", anos mais tarde já era mais sofisticada já trazia um número maior de ítens : :nome dos profissionais, cenário, direção, gerentes de projeto, analistas de projeto, número da prancha, local de gravação e data de revisão. Trata-se de uma ficha mais complexa que a anterior sugerindo maior divisão de trabalho. Além disso, toda a consulta da produção de arte pode ser consultada através de fichas digitalizadas. São elementos visuais que consistem em facilitar o trabalho para a produção de cenários e figurinos. Fotos, desenhos e caricaturas de motivos tais como: tipos de tecidos e rendas, móveis, sala de estar, tapetes, bule para chá, vaso 
chinês, faqueiro entre outros. Nestas fichas constam os seguintes ítens : tema ou nome d peça, descritor, marco histórico da época retratada, tipo de arquivo, função do arquivo e dados técnicos1. software e versão- extração, tamanho em $\mathrm{MB}$, código 2. gestão- restrição do documento, restrição do jurídico, recomendação do jurídico. Há também fichas que se referem à caracterização : em uma prancheta a foto do ator de perfil esquerdo, no meio, os reparos a serm feitos (pintar cabelo, acrescentar pelos na sobrancelha, costeleta e etc) e na foto seguinte o resultado das mudanças anteriormente citadas com utilização do photoshop.

Sob o ponto de vista da visualidade ainda podemos dizer que apesar dos avanços de cenografia, especialmente com Mario Monteiro, cenógrafo de Primo Basílio a qualidade visual avança, mas há ainda uma restrição com as técnicas, câmeras e iluminação. Pode-se dizer que a força da narrativa ainda continua sendo a interpretação, como por exemplo, a atuação de Toni Ramos no momento em que descobre que seu personagem, Jorge, foi traído. São duas câmeras Ikegami que captam com maestria, por ângulos diferentes. a dor e a raiva daquele momento. No caso de Os Maias, as câmeras mais sofisticadas., edição eletrônica e efeitos de pós produção implica uma diluição dos personagens na estética da imagem. Como observa Luis Fernando Veríssimo na apresentação do DVD que seguiu a minissérie :

A câmera extraordinariamente móvel do Luiz Fernando Carvalho "frequentou", mais do que retratou, a frívola Lisboa da época e todas as atmosferas do romance. Mas no fundo havia aquela progressão majestosa, desde a primeira cena, para o desenlance, a câmera andante nos levando como um lento tema trágico que repassa uma sinfonia. Nunca uma câmera de TV foi tão cúmplice e envolvente,nunca a TV foi tão romântica" .

Observa-se assim que em 2001 a a televisão já aprimora a linguagem televisiva de modo que os recursos visuais integrem de maneira mais intrínseca à própria narrativa.

\section{CONSIDERAÇÕES FINAIS}

Esta pesquisa ainda deve ser mais aprofundado, mas esperamos ter argumentado sobre a premissa dos teóricos do campo das Materialidades da Comunicação que consiste em pensar que os objetos não somente se prestam a expressar um sentido para a narração, mas no fato de que, através da sua tematização podemos conhecer muito de um fenômeno social. Assim apontamos e 
exploramos a hipótese de que a Rede Globo (re) configura e (re) apropria aspectos da vida social portuguesa dentro da visão de mundo específica e potencial tecnológico datado da empresa. Evidentemente ainda precisaremos aprimorar as comparações entre os objetos identificados nas minisséries e imagens do vestuário, mobiliário e decoração do século XIX encontrados em desenhos, pinturas e livros históricos no sentido de avaliar o grau de liberdade assumido pela emissora ao efetuar aproximações, desvios ou estilizações da época retratada. Mas já antevemos certa glamourização efetuada pela Rede Globo sobre os dados históricos como observa o consultor e cenógrafo português Antonio Casimiro. Ele comenta a respeito da alimentação e dos ornamentos.

Não se comia com tanta abundância na manhã na burguesia. Era só pão com manteiga, pão torrado.O café da manhã não era assim.. Muito abundante, frutas. Os almoços não eram assim. Não se comia bacalhau assim. Bacalhau era comida de pobre. As vezes de se tratar maneira de se comprimentar também era errada. Ainda a personagem Juliana, a cozinheira estava mal caracterizada. Marília apareceu com ornamentos de ouro, enfeitada mas não era assim. (Entrevista concedida para as autoras)

Há que se pensar neste aspecto de glamourização a partir de questões de identidade e aculturações relativas ao Brasil e Portugal, o que abre para um desdobramento desta pesquisa. Aliado à glamourização temos uma linguagem visual que se torna mais sofisticada e busca uma especificidade para a televisão que já não é mais somente a interpretação de atores diante das câmeras, mas estética da imagem. Isto é o que demonstra a riqueza de detalhes, luzes e texturas de Os Maias. Finalmente pode-se dizer que a produção das imagens obedece hoje a um ritmo industrial que pode muito bem ser convertida em fórmula. Mas, felizmente, não tem sido isso que tem acontecido nas minisséries, pelo menos nestas que estudamos.

\section{REFERÊNCIAS}

FELINTO Erick; ANDRADE, Vinícius. A Vida dos objetos: um diálogo com o pensamento da materialidade da comunicação. Revista Contemporânea. Salvador: Programa de Pósgraduação em Comunicação e Cultura Contemporâneas da Universidade Federal da Bahia, volume 3, n.1, janeiro/junho 2005. 
FLORY, Suely F.V; e MOREIRA; L.C.M. de Miranda; Uma Leitura do Trágico na Minisserie “Os Maias”. São Paulo: Arte \& Ciência, 2006.

FOUCAULT, Michel. A arqueologia do saber. Rio de Janeiro: Forense Universitária, 2004

GUMBRECHT, Hans Ulrich. Corpo e forma: ensaios para uma crítica não hermenêutica.

Rio de Janeiro, Ed UERJ, 1998

JARDIM, Silvia J. Esquadrão da Moda: participação e envolvimento no vestir da sociedade tecnológica contemporânea in $4^{\circ}$ Colóquio de Moda, Novo Hamburgo, 2008.

MCluHAN, Marshall. Os Meios de Comunicação Como Extensões do Homem, São Paulo, Ed. Cultrix, 2002.

PAIVA, Élica Luiza e MOREIRA, L.C.M. de Miranda. O Primo Basílio: um estudo do processo de transcodificação da narrativa literária para a narrativa televisual. Revista de Recensão de Comunicação e Cultura, texto da Biblioteca online de Ciências da Comunicação. s/d POIRIER, Jean. História dos Costumes - O Homem e O Objecto. Lisboa, Ed. Estampa, terceiro volume, 1999.

ROCHA, João Batista. Cenário Televisivo: linguagens múltiplas fragmentadas. São Paulo, Ed Annablume, FAPESP, 2009.

QUEIROZ, Eça de. Os Maias, São Paulo, Ed. Martin Claret, 2008, ano da primeira edição 1888. O Primo Basílio. São Paulo, Ed Ática, 2008,22º edição

ROCHA, João Carlos. O Universo das Formas Míticas em Star Trek-Jornada nas Estrelas, dissertação de Mestrado, Universidade Paulista, UNIP, 2005.

Original recebido em: 04/11/2011

Aceito para publicação em: 29/11/2011

Resumo sobre o autor

Solange Wajnman.

Pós-Doutora pela Escola Superior de Teatro, Cinema de Lisboa (ESTC) Doutora em Sociologie pela Sorbonne, Paris Professora do Programa de mestrado em Comunicação e Cultura Midiática da Universidade Paulista (UNIP) 
$M^{\mathrm{a}}$ Gabriela S.M.C. Marinho.

Doutora em História Social pela Universidade de São Paulo (USP). Professora do Programa de Mestrado em Ciências Humanas e Sociais da Universidade Federal do ABC (UFABC). 